\title{
Development of an anti-loosening fastener and comparing its performance with different other threaded fasteners
}

\author{
BIKASH PANJA and SANTANU DAS* \\ Department of Mechanical Engineering, Kalyani Government Engineering College, Kalyani 741235, India \\ e-mail: b.panja_86@yahoo.co.in; sdas.me@gmail.com
}

MS received 13 November 2013; revised 20 June 2016; accepted 30 April 2017; published online 8 September 2017

\begin{abstract}
Threaded fasteners are widely used for temporary joining of different components that require occasional disassembling. However, threaded fasteners may have the problem of loosening under vibrating conditions, which may lead to decreasing clamping force and, thereby, a system failure. In the present experimental investigation, anti-loosening ability of various fastening elements, such as conventional nut, nylock nut, flat washer, spring washer, inside and outside serrated washer, is tested with a conventional M16 high-tension steel bolt. A hybrid double nut is used to clamp the plates in which a conventional nut is used to tighten first, and one nylock nut is then placed at the outer side for further tightening. An adhesive-bonded nut is also tested, where an adhesive is placed between bolt and nut threads. All these fasteners are tested in terms of their loosening characteristics. Accelerated vibrating conditions are used for the test on an indigenously made test rig. A split bolt with taper pin is introduced for the first time to reduce loosening of fasteners. The split bolt with taper pin shows considerably good anti-loosening property compared with other threaded fasteners tested in this work.
\end{abstract}

Keywords. Threaded fastener; metric thread; bolt; nut; washer; loosening; vibration.

\section{Introduction}

Threaded fasteners have wide temporary joining applications in manufacturing assembly, servicing and repair work, etc. However, these fasteners have an inherent problem of loosening under vibration. Several anti-loosening fasteners were introduced in the past with an aim to prevent loosening of threaded fasteners under vibratory conditions as detailed by Sase et al [1], Fujii and Sase [2], Saha et al [3] and Bhattacharya et al [4].

Hongo [5] conducted some experiments long ago on variable axial loading of threaded fasteners as regards their loosening tendency. He proposed causes of loosening as reduction in axial tensile force of the bolt and plastic elongation of the bolt thread. Paland [6] also tested various types of threaded fasteners for axial loading, and made the rule of loosening. In another work, Junker [7] described the theory of self-loosening of preloaded bolted joint when subjected to vibratory condition. He observed that as soon as the friction force within the two solid bodies is overcome by the external force effective in a direction, an additional movement in another direction can result from the force that can be lesser than the friction force. Sase et al [8] tested the effectiveness of different type of threads, washers and available locking nuts of a few sizes in resisting

*For correspondence loosening. They noticed that most of the popularly known anti-loosening fasteners did not possess desired resistance to loosening.

Differential thermal effects, applied forces on the joint and bending of parts result in the relative motion in the threads, leading to loosening. One cause of loosening is the relative motion between the nut and the bolt, and the other is the relative motion between the nut/bolt and clamped surfaces $[2,4,7]$. Loosening can be minimized by change of thread design, use of various locking nuts and suitable other locking arrangements. A typical design of thread with reduced lead angle, or quite less flank angle, or reduced relative slip between bearing surface of nut and fastened material by some means minimizes loosening caused by relative rotation, as elaborated in Sase et al [1], Fujii and Sase [2], Bhattacharya et al [4] and Paland [6].

Friction-locking categories can be sub-divided into two groupings: metallic and non-metallic. The metallic frictionlocking fastener usually has a distorted thread that provides a prevailing torque. Non-metallic friction-locking devices have plastic inserts, which provide a thread locking effect, like a nylock nut $[4,8]$. In chemical locking, an adhesive such as loctite fills the gaps between the male and female threads and bonds them together, greatly reducing the loosening tendency [1-3]. A free-spinning-type fastener was reported $[4,8]$, which has a bolt with a circumferential 
row of teeth under the washer head, which was demonstrated to be a good anti-loosening fastener. Sase et al [1], Fujii and Sase [2], Sase et al [8] and Sase and Fujii [9] introduced a new shape of bolt thread profile, named steplock bolt. It had a few steps with zero lead angle at some intervals followed by helical portion at the circumference of the bolt thread. This step lock bolt was reported to show remarkable anti-loosening property. An aero-tight nut was also developed that is nothing but a torque prevailing nut of all-metal construction. It has slots at two places, which are bent slightly inwards and downwards against the bolt thread to resist loosening tendency $[1,4]$.

Saha et al [3] and Bhattacharya et al [4] developed a test rig to provide repetitive shear force acting perpendicular to the bolt axis. Saha et al [3] tested different combinations of M10, M16, BSW 3/8 and BSW 5/8 threaded fasteners to observe good resistance to vibration rendered by a nylock nut. Bhattacharya et al [4] varied clamping forces and fastening materials for both metric and BSW threads in an experimental work to observe their respective effects on loosening under vibration. Different washers and nuts were used in another investigation by Mahato and Das [10] on BSW 3/8 threaded parts, and in these tests also, a nylock nut was found to show good anti-loosening nature. BSW 3/8 hybrid nut, a combination of an inside conventional nut and a nylock nut at the outer end, was reported by Samanta et al [11] to give good locking tendency against vibration due to enhanced friction and to retain preload.

Basava and Hess [12] observed that axial vibration at some cases might cause loss of clamping force, whereas Pai and Hess [13-15] experimentally investigated the loosening characteristics of nut-bolt-washer combine under dynamic shear load. On the other hand, Rashquinha and Hess [16] tried to simulate the loosening behaviour of the threaded fasteners by modelling nonlinear dynamics of the system under varying load conditions. Investigations on loosening characteristics under transverse vibration condition and shock loading condition were carried out by Zadoks and Yu [17] and Dong and Hess [18], respectively. Zadoks and Yu [17] made static and dynamic models to find out the main reason behind self-loosening of bolted joints. Impact loading between the clamped components and the bolt was observed to be the cause of their loosening. The model developed was also used for loosening prediction. Shock loading was also investigated as a cause of loosening of threaded fasteners by Dong and Hess [18].

Three-dimensional FEM analyses were also applied by Pai and Hess [13, 14] and Izumi et al [19, 20] for better understanding of the situation of loosening that was validated well with the experimental data. Ibrahim and Pettit [21] analysed different kinds of fasteners including bolted joints regarding their dynamics and uncertainty of retaining the clamping torque under vibration condition.

High preload, large modulus of elasticity, big bolt diameter, tight fit and fine threads were recommended by Sanclemente and Hess [22] for good locking property of a fastening system, whereas Cheatham et al [23] showed that utilizing loctite and facilitating an adhesive bond gave better resistance to loosening than using standard and locking helicoil inserts. Eccles et al [24], in a recent work, tested and analysed the conditions for detachment of nuts from nut-bolt assembly under combined axial and shear loading conditions, while Dinger and Friedrich [25] carried out finite-element analysis to be validated by experimental results that showed the importance of the state of local contact in causing slip between two contact surfaces, resulting in loosening of threaded fasteners, or resistance to slip under vibrating condition.

In the present work, first, tendency of loosening of a number of existing threaded fasteners is explored. Next, new threaded fasteners, namely split bolt with taper pin and hybrid double nut, are introduced, and their performance in comparison to the others tested is discussed.

\section{Details of experimentation}

An indigenously developed test rig, as reported by Bhattacharya et al [4], is modified for carrying out experiments to judge the anti-loosening ability of some threaded fasteners. Modifications made in this set-up are replacement of worn out cam with a new hardened one, and replacing the existing spring with a higher-stiffness spring to increase striking force during cam action and promote acceleration test. This set-up has one compression-type load cell and an indicator (make-Sushma, Bengaluru, India, model: SLC302) to observe the clamping force within the threaded assembly.

A plate is fastened perpendicular to the bolt axis; using a cam, strikes are made perpendicular to the bolt axis, that is, parallel to the flat face of the fastened plate. Repeated strikes at a frequency of 300 strokes/min and $0.2 \mathrm{~mm}$ amplitude onto the clamped loose plate are provided to facilitate the accelerated loosening test. The mechanisms of using the cam are shown in figure 1 . The working principle of the set-up can be easily understood from the schematic diagram shown in figure 2. During the test, fasteners may loosen, which indicates the corresponding decrease in clamping force. This decrement in clamping force with the passage of testing time is noted, and plotted in graphical representation.

Different combinations of M16 threaded fasteners are used for loosening tests. The standard metric threaded fastener has $1.5 \mathrm{~mm}$ pitch and $60^{\circ}$ thread profile. First, a conventional high tension steel (HTS) bolt with a conventional nut is tested. Next, experiments are carried out using a flat washer, or spring washer, or serrated washer (inside or outside) (shown in figure 3) with conventional nut and bolt. A nylock nut (figure $3 \mathrm{a}$ ) and an adhesive-bonded nut on a standard bolt are also tested, to explore their anti-loosening tendency. A newly introduced hybrid double nut and a new 


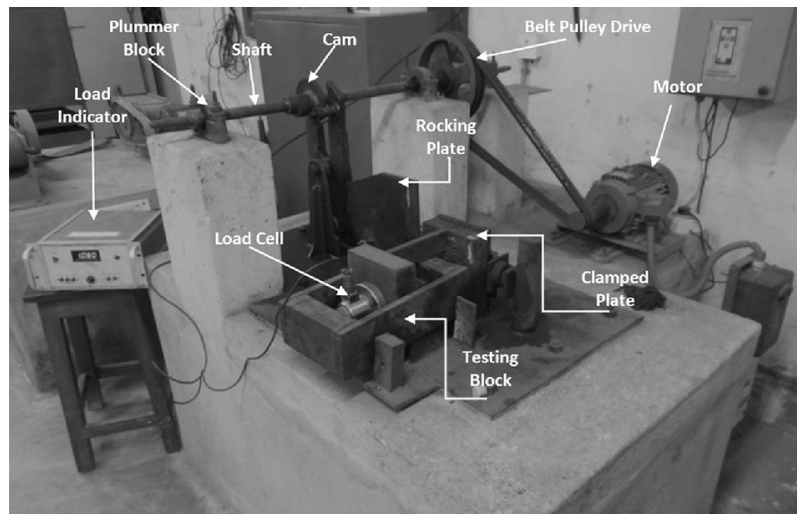

Figure 1. Pictorial view of the test rig.

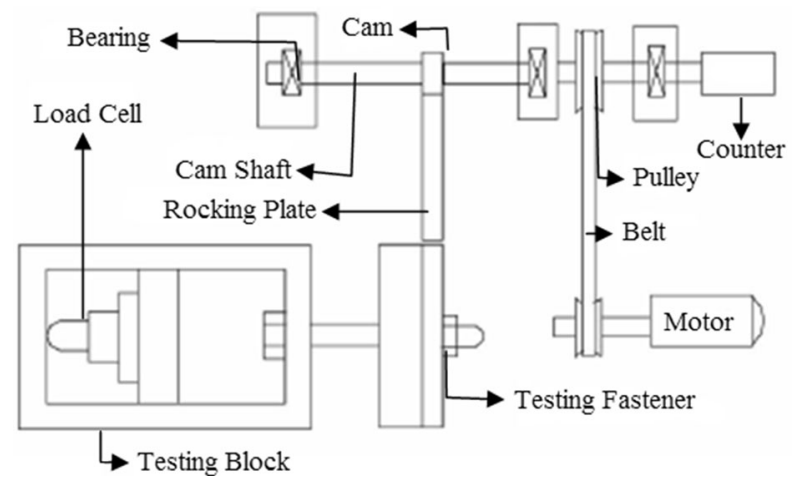

Figure 2. Schematic diagram of the test rig.

concept of using a split bolt with taper pin with a standard nut are also investigated to undertake loosening test without using any washers. Some of these fasteners, such as washers, nylock nut, etc., are believed to exhibit locking tendency under vibration. Tests are conducted to verify the extent of anti-loosening ability they have in actuality in this particular test condition. Next, series of experiments are taken up to investigate the resistance to loosening exhibited by the newly introduced hybrid double nut and split bolt with taper pin at the same experimental condition. In this work, all their loosening tendencies are explored to compare their resistance to loosening against vibration as detailed in table 1. Each test is repeated once to find out variations of results obtained.

An adhesive-bonded nut is also tested in this work that aims at locking the threaded fasteners with the use of an adhesive. The adhesive fills the gap between the nut and bolt threads and bonds them together. An epoxy-based high-strength adhesive, Araldite (Mechanik), is used in the present work. It is a standard epoxy adhesive made by Huntsman Advanced Materials (India) Pvt. Ltd. Thickness of the adhesive is not more than $1 \mathrm{~mm}$. For the sake of disassembly, a torque slightly more than the clamping torque needs to be applied to cause the nut to come out without much difficulty.

The hybrid double nut used in the present work is a combination of one conventional nut and one nylock nut. A typical nylock nut is shown in figure 3a. In this case, first a conventional nut is used to clamp the components and then a nylock nut is used for final tightening from outside, keeping the conventional nut inside it. The additional friction gripping obtained through nylock nut is thought of as providing superior locking tendency of this double nut assembly over that of the simple conventional double nut, which is already found $[4,19,20]$ to have not much antiloosening tendency consistently.

In this work, a new concept is introduced for reduction of loosening of fasteners under vibration. This is named as 'split bolt with taper pin'. For producing a split bolt, first, an axial hole of $\phi 5 \mathrm{~mm}$ in a standard M16 HTS bolt is made at the free end such that a radial thickness of $5.5 \mathrm{~mm}$ persists at the hollow bolt end. Next, the bolt end is split symmetrically along the hole with a hack saw, such that insertion of a taper pin can expand the bolt end radially outwards. A taper pin is designed with a small taper of 1:30 slope to avoid loosening of the taper pin itself. Photograph of a split bolt is shown in figure $4 \mathrm{a}$, depicting the slit and the hole made. A taper pin made of low-carbon steel is prepared and a drilled hole $(\phi 5 \mathrm{~mm})$ is made into its head to get another pin $(\phi 4.5 \mathrm{~mm})$ inserted into it. This pin facilitates withdrawal of the taper pin from bolt hole by striking with a light hammer when disassembly of components is required. Pictorial view of a taper pin and the other pin are presented in figure $4 \mathrm{~b}$ and dimensions of the taper pin are given in figure 4c. Dimension of the pin is selected by the hit and trial method.

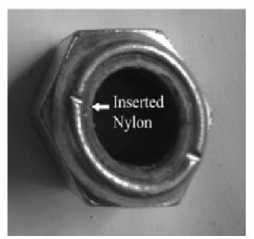

(a)

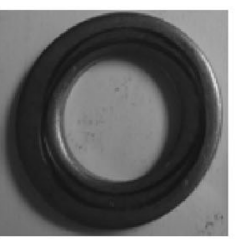

(b)

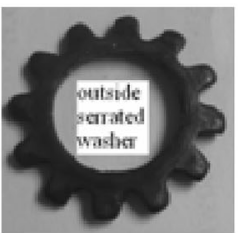

(c)

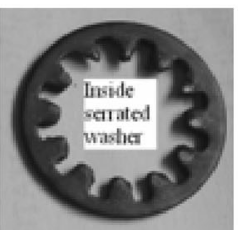

(d)

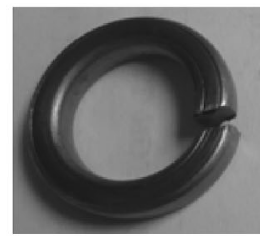

(e)

Figure 3. Different fastening elements tested: (a) nylock nut, (b) flat washer, (c) outside serrated washer, (d) inside serrated washer and (e) spring washer. 
Table 1. Description of fasteners using high-tension steel used in experiments.

\begin{tabular}{|c|c|c|c|}
\hline $\begin{array}{l}\text { Sl. } \\
\text { no. }\end{array}$ & Type of bolt & Nut used & Washer used \\
\hline 1 & M16 × 230 & $\begin{array}{c}\text { Conventional } \\
\text { nut }\end{array}$ & - \\
\hline 2 & M16 × 230 & $\begin{array}{c}\text { Conventional } \\
\text { nut }\end{array}$ & Flat washer \\
\hline 3 & M16 × 230 & $\begin{array}{c}\text { Conventional } \\
\text { nut }\end{array}$ & Spring washer \\
\hline 4 & M16 × 230 & $\begin{array}{c}\text { Conventional } \\
\text { nut }\end{array}$ & $\begin{array}{c}\text { Inside serrated } \\
\text { washer }\end{array}$ \\
\hline 5 & M16 × 230 & $\begin{array}{c}\text { Conventional } \\
\text { nut }\end{array}$ & $\begin{array}{c}\text { Outside serrated } \\
\text { washer }\end{array}$ \\
\hline 6 & M16 × 230 & Nylock nut & - \\
\hline 7 & M16 × 230 & $\begin{array}{c}\text { Hybrid double } \\
\text { nut }\end{array}$ & - \\
\hline 8 & M16 × 230 & $\begin{array}{l}\text { Adhesive- } \\
\text { bonded nut }\end{array}$ & - \\
\hline 9 & $\begin{array}{l}\text { Split bolt } \\
\text { M16 } \times 230\end{array}$ & $\begin{array}{c}\text { Conventional } \\
\text { nut }\end{array}$ & - \\
\hline
\end{tabular}

When components are clamped using the nut-bolt system with a usual clamping torque and force, the tapered pin is inserted inside the hole at the split bolt end by a light hammer. This causes secured insertion of taper pin inside the bolt, resulting in a small expansion of split end of the bolt within the nut. This imparts tightening of nut onto the bolt and is, thereby, expected to have enough resistance to loosening under vibration. A photograph of the assembled split bolt with pin is also shown in figure $4 \mathrm{~d}$. In this figure, the taper pin is inserted into the split bolt by $20 \mathrm{~mm}$.

\section{Results and discussions}

Results obtained with M16 HTS bolts fitted with various fastening elements are shown in figures 5-14. From the experiment on conventional M16 HTS bolt with conventional nut, results obtained are shown in figure 5. A reduction of about $6 \%$ of clamping force for experiment 1 after 5000 oscillations is experienced. Experiment 2, which is a repeat of experiment 1 , shows loosening of about $4 \%$ of tightening force. Clamping force shows a continuously decreasing trend even at a quite slow rate towards 5000 oscillations.

Figure 6 shows the loosening tendency of M16 HTS bolt with a flat low-carbon steel washer. It is observed that the use of flat washer reduces the loosening only to a small extent. In two similar experiments, total losses of clamping forces observed are around $4 \%$ in experiment 1 and $3 \%$ in experiment 2. This loosening is only slightly lesser than that with conventional nut and bolt as seen in figure 5 . Thus, the popular belief of obtaining the anti-loosening
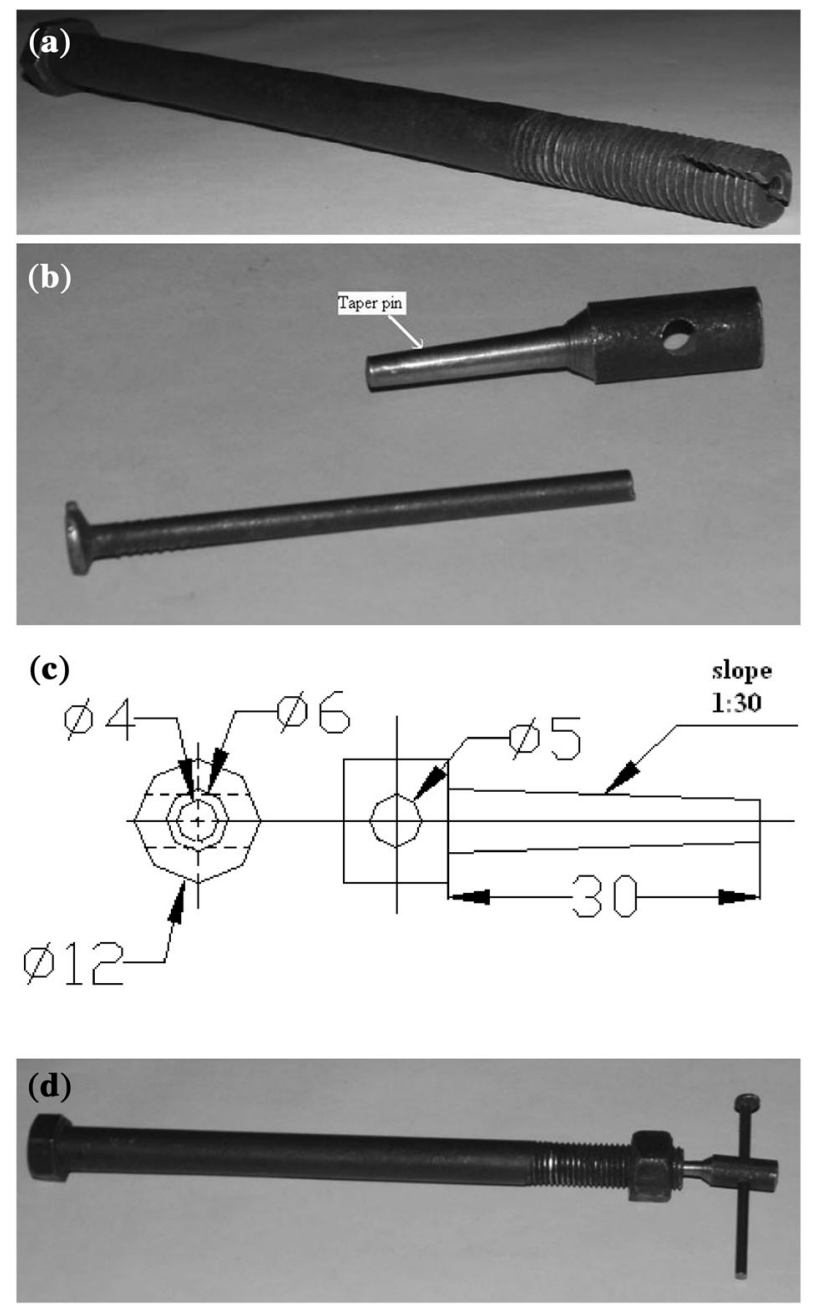

Figure 4. (a) Photograph of split bolt $(\mathrm{M} 16 \times 230)$. (b) Views of taper pin and other pins of $\phi 4.5 \mathrm{~mm}$. (c) Dimensions of the taper pin used. (d) Photograph of the M16 × 230 split bolt and pin assembly.

characteristics of flat steel washer is not supported by these experimental results. This is in line with the previous observations reported by Sase et al [1], Fujii and Sase [2], Saha et al [3], Bhattacharya et al [4] and Mahato and Das [10].

Trends of loosening of the M16 HTS nut and bolt with spring washer for two repeat tests conducted under vibration condition are shown in figure 7 . Results of experiments 1 and 2 at this condition are quite close to each other. The average loosening obtained is about $3.5 \%$ after 5000 oscillations. Thus, the spring washer decreases loosening slightly more than the flat washer. Retention of tightening load due to restoration of spring force and the small indentation of spring washer ends may have rendered this small resistance to loosening.

Figure 8 shows the loosening characteristics of conventional M16 HTS bolt and nut with inside serrated washer under similar vibratory condition. Here, about $3 \%$ and $3.3 \%$ 


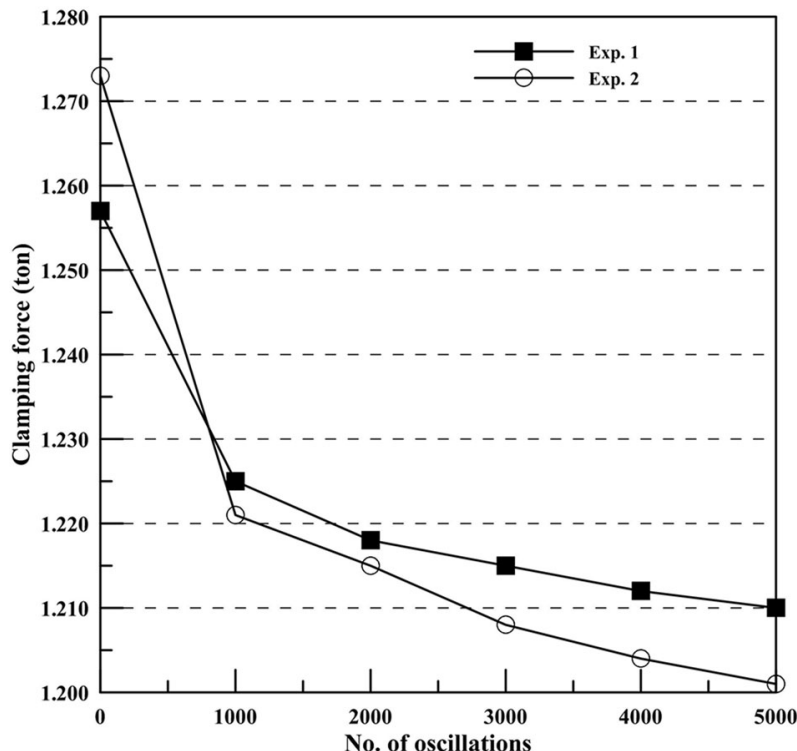

Figure 5. Test results for M16 high tension steel bolt with conventional nut under vibration.

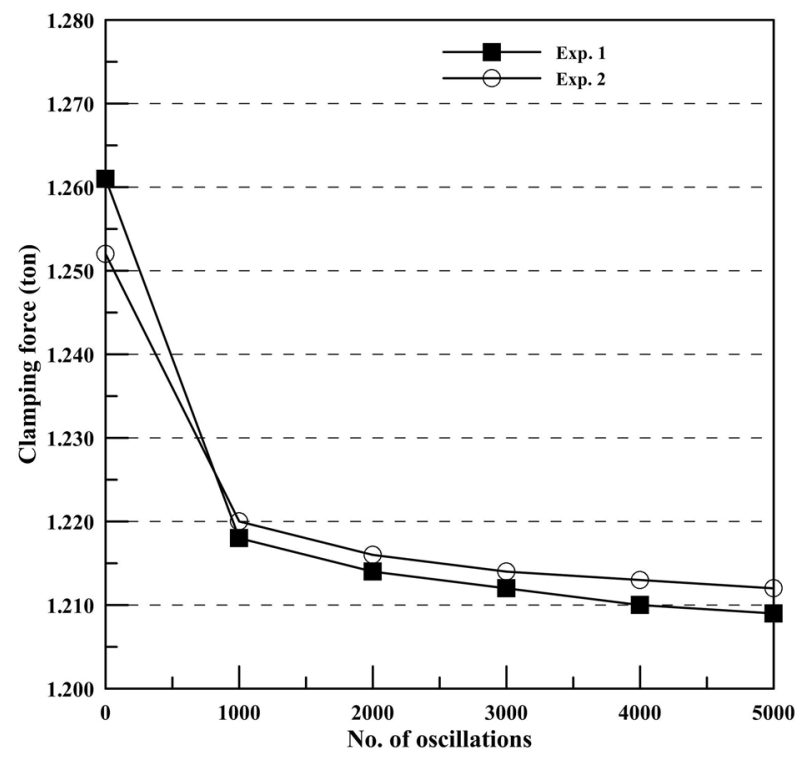

Figure 6. Test results for M16 high tension steel bolt with flat washer under vibration.

of clamping forces are lost in experiment 1 and experiment 2 , respectively, after 5000 oscillations.

Loss of clamping force with the number of oscillations of vibration is depicted in figure 9 for M16 HTS threaded fasteners with outside serrated washer, where experiments 1 and 2 results are found to be quite close to each other. The average loosening is about $2.5 \%$ after 5000 oscillations.

Both the plots (figures 8 and 9) show that the use of serrated washer (inside or outside) provides more resistance to loosening compared with flat washer (figure 6) and spring washer (figure 7). This may be due to the fact that

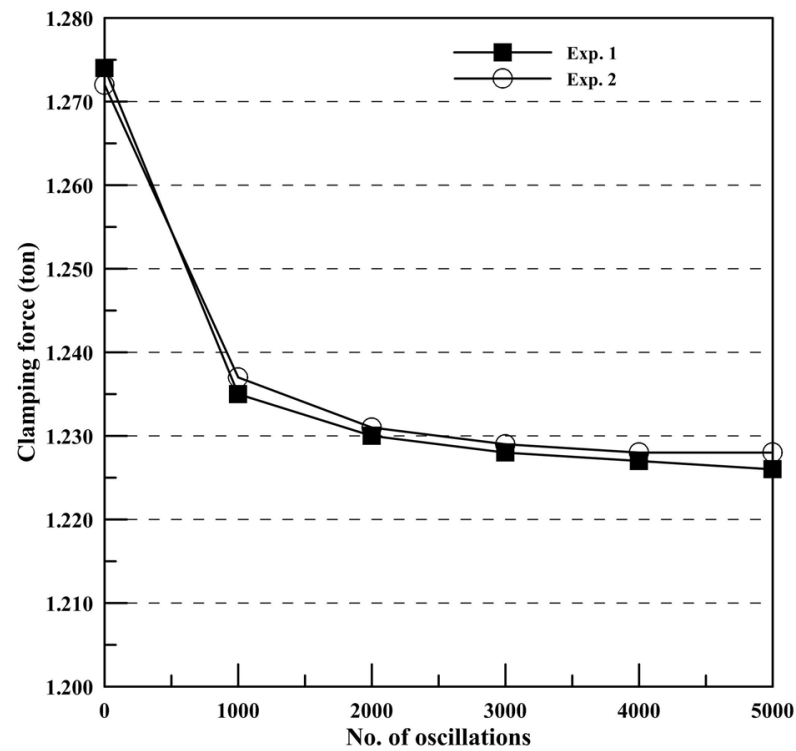

Figure 7. Test results for M16 high tension steel bolt with spring washer under vibration.

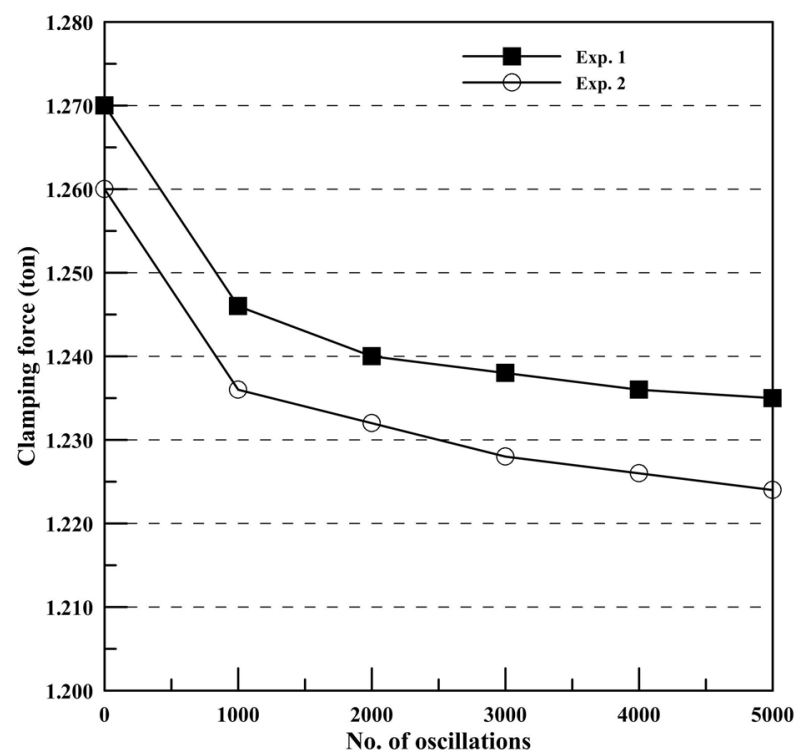

Figure 8. Test results for M16 high tension steel bolt with inside serrated washer under vibration.

serrated washers are expected to have certain deformation onto the face of nut and clamped plate, to increase interfacial friction, resulting in resistance to loosening.

Figure 10 shows the loosening characteristics of the nylock nut used on a conventional M16 HTS bolt for two similar tests without using any washer. Both of the curves become almost flat and parallel to each other after about 5000 oscillations, indicating no considerable loss of clamping force. Results suggest that for the nylock nut, total loosening is low and $1.5 \%$ in average for both experiments. As a nylock nut provides an extra friction grip 


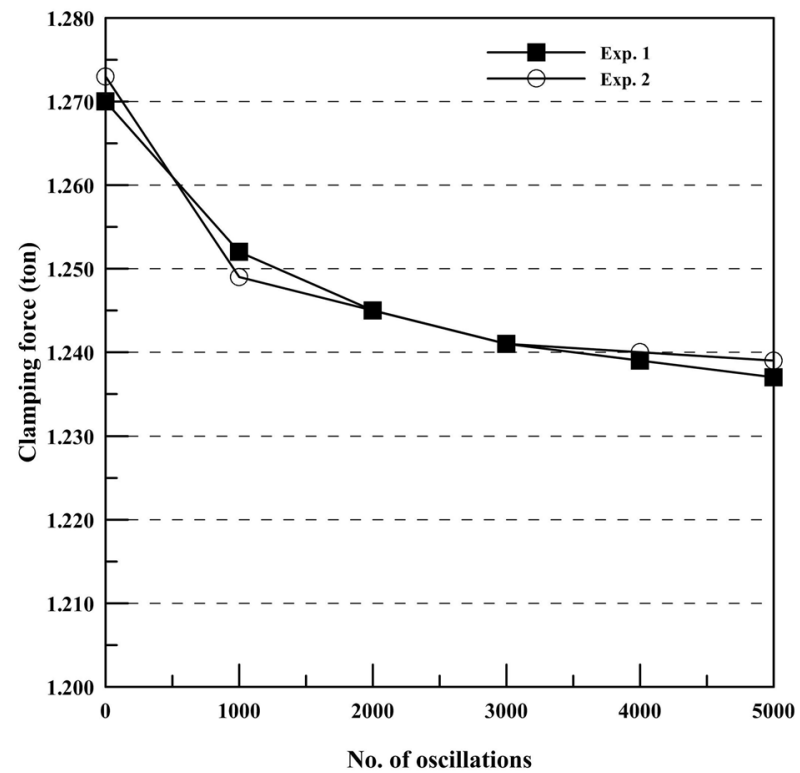

Figure 9. Test results for M16 high tension steel bolt with outside serrated washer under vibration.

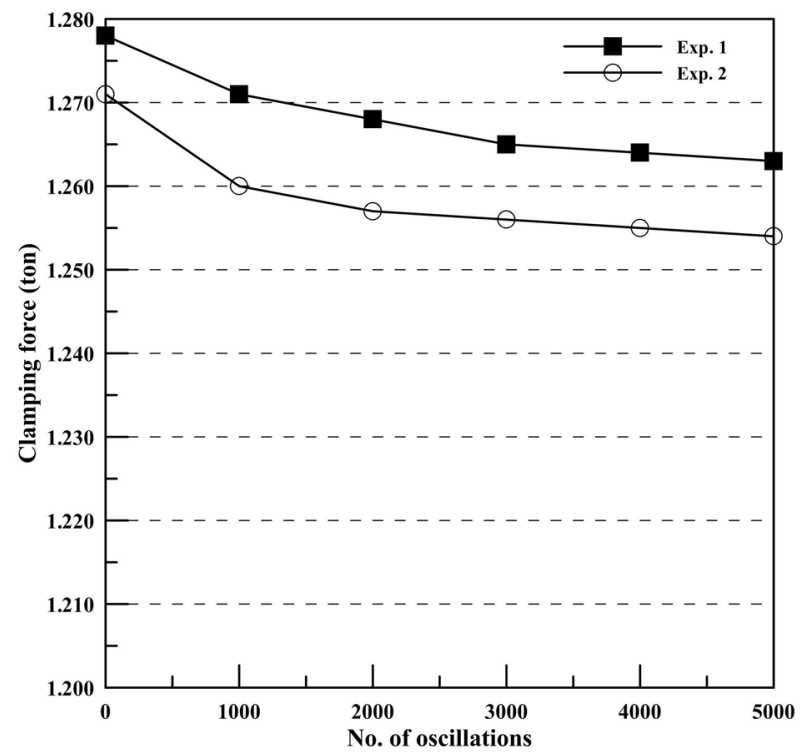

Figure 10. Test results for M16 high tension steel bolt with nylock nut under vibration.

on the bolt thread, it naturally resists loosening to a large extent. Similar results were also found in the experiments of Sase et al [8], where nylock nut gave better resistance to loosening compared with conventional nut with and without a washer.

Figure 11 shows the loosening characteristics for an M16 HTS bolt with one conventional nut and one nylock nut, named together as a hybrid double nut, subjected to a similar kind of vibration as employed in other tests in this work. From this figure, it is observed that the use of this hybrid double nut in place of single nylock nut can resist

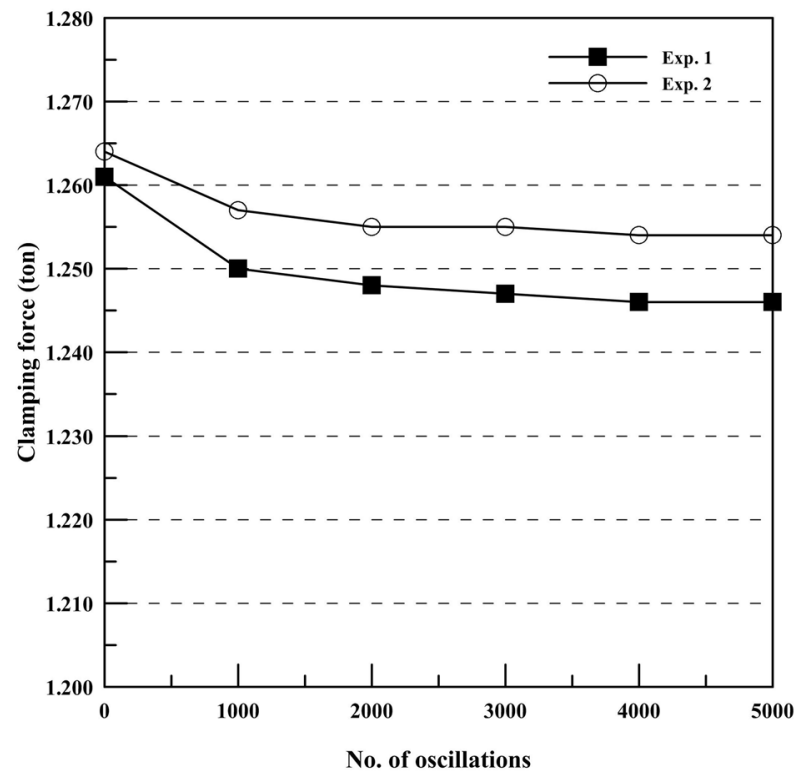

Figure 11. Test results for M16 high tension steel bolt with hybrid double nut (one conventional nut and one nylock nut) under vibration.

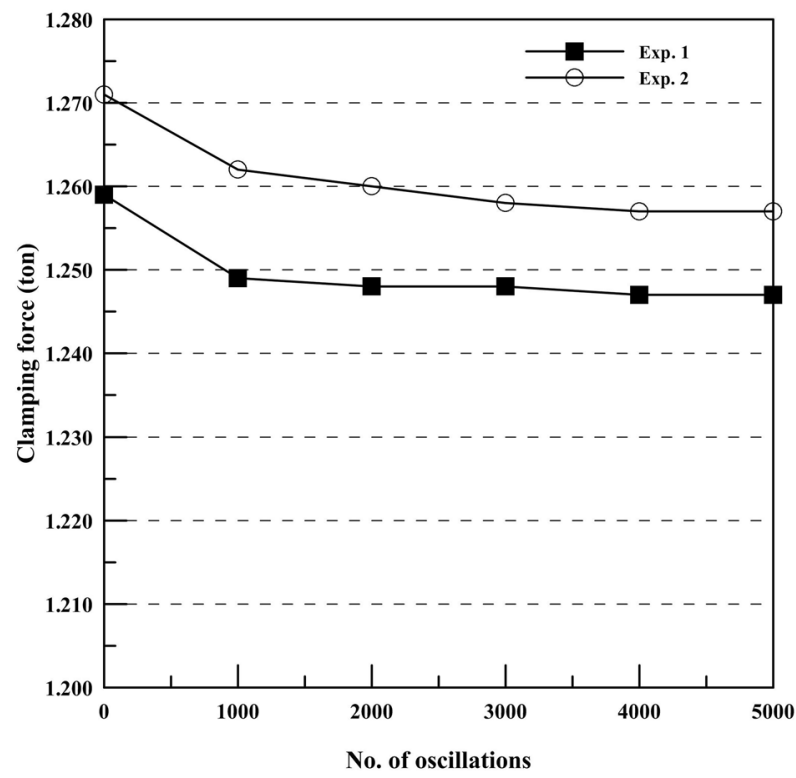

Figure 12. Test results for M16 high tension steel bolt with adhesive-bonded conventional nut under vibration.

loosening quite effectively. In both experiments, loss of clamping force is found to be $1.4 \%$ in experiment 1 and $1 \%$ in experiment 2 after 5000 oscillations. Effect of retention of tightening torque by the friction gripping of nylock nut and that of the effect of preloaded double nut may have resulted in this result.

Figure 12 shows the loosening characteristics for HTS M16 metric bolt with adhesive (Araldite) bonded conventional nut without using any washer. Use of the adhesive- 


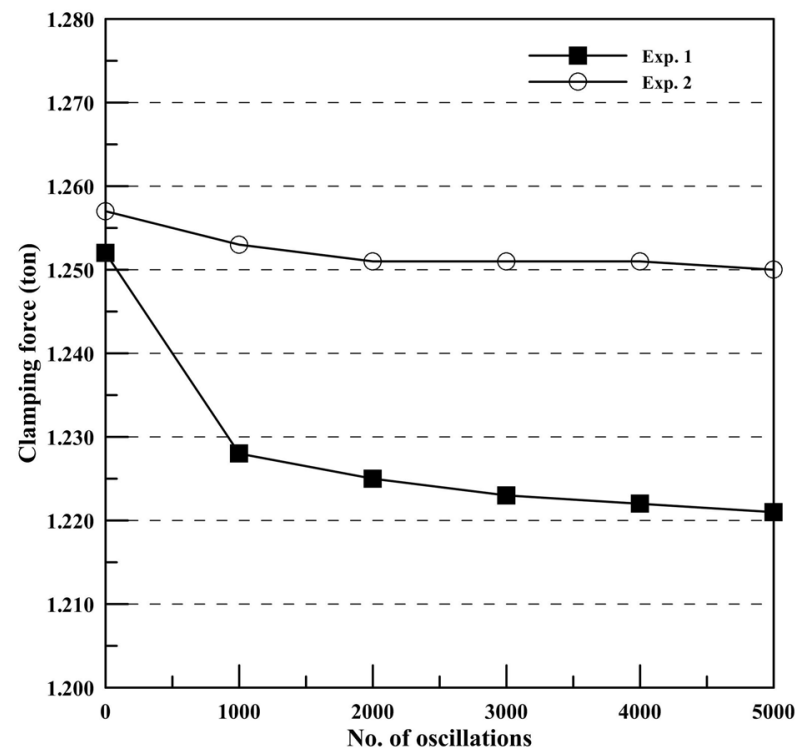

Figure 13. Test results for split bolt of M16 mild steel bolt with taper pin along with conventional nut under vibration.

bonded nut provides more resistance to loosening compared with nylock nut. Average loosening of clamping forces for both experiments is about $1 \%$, and it occurs up to about 4000 oscillations. After this, there is no appreciable reduction in clamping force up to 5000 oscillations. This observation shows anti-loosening nature almost similar to that using the hybrid nut (figure 11). The adhesive gets secured between nut and bolt threads and raises the friction greatly, thereby remarkably arresting the loss of tightening torque or force.

Figure 13 shows the loosening characteristics of the newly developed split bolt with taper pin and conventional nut. When the bolt diameter is expanded by $0.62 \mathrm{~mm}$ by inserting the taper pin into the hole inside the split bolt at the free end, the loosening of clamping force is about $2.5 \%$. Expanding bolt diameter by $0.86 \mathrm{~mm}$, by pushing the taper pin much inside the split bolt hole, causes loss of clamping force by only $0.8 \%$ after 5000 oscillations. It is clear from figure 13 that after 2000 oscillations, no remarkable loss of clamping force is detected. Higher radial load onto the nut thread pressed by threads of expanded split bolt may have caused less loosening tendency. Expansion of $0.62 \mathrm{~mm}$ shows better resistance to loosening than those of the spring washers. However, expansion of $0.86 \mathrm{~mm}$ in bolt diameter gives more antiloosening ability than that of the nylock nut, hybrid double nut and adhesive-bonded nut. Hence, split bolt with taper pin along with conventional nut can be used to arrest loosening effectively provided appropriate expansion of the split bolt is undertaken. Split bolt with taper pin along with conventional nut can resist loosening effectively, because relative slip between the nut and bolt can be minimized by reducing thread gap between nut and bolt to a large extent due to expansion of diameter on bolt thread with the help of a taper pin.

Table 2 shows the initial clamping force for each replicated experiment corresponding to each set of experiments. Figure 14 is constructed by considering the plots corresponding to higher loosening tendency for each set of experiments using M16 HTS bolt with different nuts and washers. The conventional nut and bolt naturally shows the maximum loss of clamping force in the present experimental conditions. Figure 14 also depicts high loss of tightening force when a flat metal washer is used with the conventional nut and bolt, indicating insignificant effect of the use of a flat metal washer. Relative to the flat washer, a spring washer reduces loss of clamping force to a considerable extent. Inside and outside serrated washers can also reduce rate of loosening to some extent. Spring and serrated washers, when subjected to tightening torque, cause some indentation in the plate and nut on bearing surfaces, as also seen after experimentation; thereby, this increases contact friction and tendency to suppress loosening of fastening elements.

Good amount of friction grip due to a nylon insert within a nylock nut without any washer gives considerable

Table 2. Tabular representation of the results obtained with 5000 oscillations.

\begin{tabular}{|c|c|c|c|c|c|c|c|}
\hline \multirow[b]{3}{*}{ Sl. no. } & \multirow[b]{3}{*}{ Type of bolt } & \multirow[b]{3}{*}{ Nut used } & \multirow[b]{3}{*}{ Washer used } & \multicolumn{4}{|c|}{ Clamping force (ton) } \\
\hline & & & & \multicolumn{2}{|c|}{ Exp. 1} & \multicolumn{2}{|c|}{ Exp. 2} \\
\hline & & & & Initial & Final & Initial & Final \\
\hline 1 & M16 × 230 & Conventional nut & - & 1.257 & 1.211 & 1.273 & 1.201 \\
\hline 2 & M16 × 230 & Conventional nut & Flat washer & 1.261 & 1.210 & 1.252 & 1.213 \\
\hline 3 & M16 × 230 & Conventional nut & Spring washer & 1.274 & 1.226 & 1.272 & 1.228 \\
\hline 4 & M16 × 230 & Conventional nut & Inside serrated washer & 1.270 & 1.236 & 1.260 & 1.224 \\
\hline 5 & M16 × 230 & Conventional nut & Outside serrated washer & 1.270 & 1.237 & 1.273 & 1.239 \\
\hline 6 & M16 × 230 & Nylock nut & - & 1.278 & 1.263 & 1.271 & 1.255 \\
\hline 7 & M16 × 230 & Hybrid double nut & - & 1.261 & 1.248 & 1.264 & 1.254 \\
\hline 8 & M16 × 230 & Adhesive-bonded nut & - & 1.259 & 1.247 & 1.271 & 1.258 \\
\hline 9 & Split bolt M16 × 230 & Conventional nut & - & 1.252 & 1.221 & 1.257 & 1.249 \\
\hline
\end{tabular}




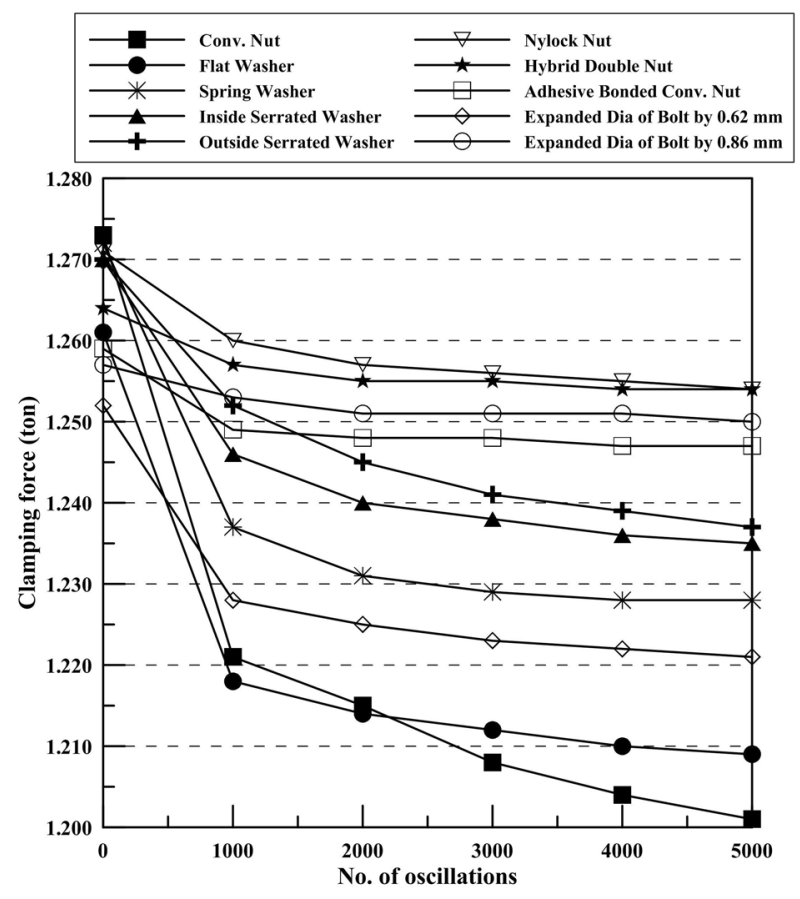

Figure 14. Comparison of loosening for M16 high tension steel bolt with different nuts and washers under vibration.

resistance to loosening compared with that obtained using different washers in the conventional nut-bolt system. However, hybrid double and adhesive-bonded nuts are found to be good anti-loosening fasteners under vibration, and after a few minutes of operations, they exhibit almost no loosening. On the other hand, use of a split bolt with taper pin, when expanded by $0.86 \mathrm{~mm}$, shows quite high resistance to loosening compared with a split bolt expanded by $0.62 \mathrm{~mm}$.

Comparing all the plots, it is observed that initially the rate of loosening is high. However, after a few minutes of operations at 300 strokes per minute, the rate of loss of clamping force becomes less.

\section{Conclusions}

From the experimental results obtained with different combinations of HTS bolt and other fastening elements, following conclusions may be drawn.

1. It is found that the conventional nut-bolt system and use of a flat washer and conventional nut-bolt are subject to considerable loosening under the vibration condition provided. Spring washer, inside washer serrated and outside serrated washer tend to provide some antiloosening tendency. A small indentation of these washers may have resulted in high contact friction, giving some resistance to loosening.
2. A nylock nut shows good anti-loosening ability and less possibility to loosen in vibrating environment due to the presence of nylon friction grip.

3. A hybrid double nut using one inside conventional nut and one nylock nut on the outside is found to prevent the loosening quite effectively compared with a single nylock nut. This may have happened due to the benefits of extra nylon grip and the preload existing within the double nut.

4. Use of the adhesive-bonded nut provides locking characteristics similar to that of a hybrid double nut due to large adhesive friction.

5. A split bolt with taper pin along with a conventional nut can resist the loosening effectively because relative slip between nut and bolt can be minimized by reducing thread gap between the nut and bolt due to expansion of diameter on bolt thread with the help of the taper pin. This bolt gives quite good anti-loosening capability when considerable split bolt expansion is provided.

6. An adhesive-bonded nut, hybrid double nut and split bolt with taper pin can be effectively used as anti-loosening threaded fasteners under vibration conditions as experienced in the present experimental domain.

\section{Acknowledgements}

The authors wish to express their sincere acknowledgement to All India Council for Technical Education, New Delhi, India, for providing the R\&D Grant (vide its sanction letter Ref. 8018/RDII/BOR/R\&D(244)/99-2000 dated March 24, 2000) with which the test rig was set up. Funding was provided by Kalyani Govt. Engineering College, Kalyani.

\section{References}

[1] Sase N, Nishioka K, Koga S and Fujii H 1998 An antiloosening screw fastener innovation and its evaluation. $J$. Mater. Process. Technol. 77: 209-215

[2] Fujii H and Sase N 1998 SLB concept for screw fastening and its anti-loosening performance. In: Souvenir of the All India Manufacturing Technology, Design and Research Conference, Kharagpur, India, pp. 25-34

[3] Saha S K, Srimani S, Hajra S, Bhattacharya A and Das S 2007 On the anti-loosening property of different fasteners. In: Proceedings of the 13th National Conference on Machines and Mechanisms, Bengaluru, India, pp. 229-232

[4] Bhattacharya A, Sen A and Das S 2010 An investigation on anti-loosening characteristics of threaded fasteners under vibratory condition. Mech. Mach. Theory 45: 1215-1225

[5] Hongo K 1964 Loosening of bolt and nut fasteners. Trans. Jpn. Soc. Mech. Eng. 30: 934-939

[6] Paland E G 1966 Investigation of the locking features of dynamically loaded bolted connections. Dissertation submitted to Hannover University, Germany 
[7] Junker G H 1969 New criteria for self-loosening of fasteners under vibration. SAE International Automotive Engineering Congress Paper 690055, pp. 934-939

[8] Sase N, Koga S, Nishioka K and Fujii H 1996 Evaluation of anti-loosening nuts for screw fasteners. J. Mater. Process. Technol. 56: 321-332

[9] Sase N and Fujii H 2001 Optimizing study of SLBs for higher anti-loosening performance. J. Mater. Process. Technol. 119: 174-179

[10] Mahato K N and Das S 2009 A study on anti-loosening characteristics of different $3 / 8$ BSW threaded fasteners. In: Proceedings of the 14th National Conference on Machines and Mechanisms, Durgapur, India, pp. 409-415

[11] Samanta S, Das S, Roy R, Bhukta K, Pal A and Das S 2012 Comparison of loosening characteristics of $3 / 8 \mathrm{BSW}$ threaded fasteners under accelerated vibratory condition. J. Assoc. Eng. 82: 34-43

[12] Basava S and Hess D P 1998 Bolted joint clamping force variation due to axial vibration. J. Sound Vib. 210: 255-265

[13] Pai N G and Hess D P 2002 Experimental study of loosening of threaded fasteners due to dynamic shear loads. J. Sound Vib. 253: 585-602

[14] Pai N G and Hess D P 2002 Three-dimensional finite element analysis of threaded fastener loosening due to dynamic shear load. Eng. Fail. Anal. 9: 383-402

[15] Pai N G and Hess D P 2003 Influence of fastener placement on vibration-induced loosening. J. Sound Vib. 268: 617-626

[16] Rashquinha I A and Hess D P 1997 Modelling nonlinear dynamics of bolted assemblies. J. Appl. Math. Model. 21: 801-809
[17] Zadoks R I and Yu X 1997 An investigation of the selfloosening behavior of bolts under transverse vibration. $J$. Sound Vib. 208: 189-209

[18] Dong Y and Hess D P 2000 Shock-induced loosening of dimensionally non-conforming threaded fasteners. J. Sound Vib. 231: 451-459

[19] Izumi S, Yokoyama T, Iwasaki A and Sakai S 2005 Threedimensional finite element analysis of tightening and loosening mechanism of threaded fastener. Eng. Fail. Anal. 12: 604-615

[20] Izumi S, Yokoyama T, Kimura M and Sakai S 2009 Loosening-resistance evaluation of double-nut tightening method and spring washer by three-dimensional finite element analysis. Eng. Fail. Anal. 16: 1510-1519

[21] Ibrahim R A and Pettit C L 2005 Uncertainties and dynamic problems of bolted joints and other fasteners. J. Sound Vib. 279: 857-936

[22] Sanclemente J A and Hess D P 2007 Parametric study of threaded fasteners loosening due to cyclic transverse loads. Eng. Fail. Anal. 14: 239-249

[23] Cheatham C A, Acosta C F and Hess D P 2009 Tests and analysis of secondary locking features in threaded inserts. Eng. Fail. Anal. 16: 39-57

[24] Eccles W, Sherrington I and Arnell R D 2010 Towards an understanding of the loosening characteristics of prevailing torque nuts. Proc. IMechE Part C: J. Mech. Eng. Sci. 224: 483-495

[25] Dinger G and Friedrich C 2011 Avoiding self-loosening failure of bolted joints with numerical assessment of local contact state. Eng. Fail. Anal. 18(8): 2188-2200 